\title{
Moral Particularism and Scientific Practice
}

\author{
Brendan Larvor
}

\begin{abstract}
Particularism is usually understood as a position in moral philosophy. In fact, it is a view about all reasons, not only moral reasons. Here I show that particularism is a familiar and controversial position in the philosophy of science and mathematics. I then argue for particularism with respect to scientific and mathematical reasoning. This has a bearing on moral particularism, because if particularism about moral reasons is true, then particularism must be true with respect to reasons of any sort, including mathematical and scientific reasons.
\end{abstract}

Keywords: ethics, moral, particularlism, science, mathematics, practice

There has lately been a wave of interest in particularism. ${ }^{1}$ This discussion has an odd feature: it has almost exclusively concerned moral particularism. This is odd because particularism is a thesis about reasons in general, not just moral reasons. The restriction of the discussion to moral reasons is a contingency. One leading particularist writer, Jonathan Dancy, claims that the debate has focussed on moral reasons because, in non-moral domains, particularism is uncontroversially true. ${ }^{2}$ The contention of this paper is that particularism is true of scientific and mathematical reasoning, but controversially so. Therefore, defenders of an unrestricted particularism about reasons must make the case for particularism with respect to nonmoral reasons, including scientific and mathematical reasons. ${ }^{3}$

In this paper, I shall first briefly characterise particularism in moral philosophy. Then, I will show that particularism is a familiar and controversial position in the philosophy of science and mathematics. I will then argue for particularism about 
scientific and mathematical reasoning. This has a bearing on moral particularism, because if particularism about moral reasons is true, then particularism must be true with respect to reasons of any sort, including mathematical and scientific reasons (unless there are grounds to treat moral reasoning as a special case, but these have not been forthcoming in the literature).

\section{What is Particularism?}

Particularism in moral philosophy is best characterised by contrast with its dialectical opposite, generalism. For generalism, reasoning is intelligible only by reference to a general principle, rule, maxim or theory. Thus, in Kantian ethics (to consider one sort of generalist), to think morally is to think in conformity with the categorical imperative. Similarly, in the philosophy of science, as I shall argue later, generalists claim that to think scientifically is to think about some specific problem in a manner consistent with the scientific method. ${ }^{4}$ Of course, generalists do not suppose that moral agents and scientists must make conscious use of philosophical theories such as Kantian ethics or the Popperian logic of science (for example). One can act in conformity with a principle or theory without consciously employing it (though it did matter to Kant that agents act for the sake of morality). Nevertheless, moral generalists hold that in order to understand moral thinking, we must appeal to something general: a principle, rule, maxim, theory or similar. For Kant, for example, lying is wrong. This is an exceptionless universal principle. When a Kantian moral agent considers telling an untruth, she examines the circumstances in order to determine whether this untruth would count as a lie. To borrow Kant's own example in the Metaphysics of Morals, it is not a lie to write "your obedient servant" at the end of a letter (Kant 1999, 431). The significant details of the case in hand have their 
significance in virtue of their relevance to the question 'would this untruth be a lie?' The principle ('Lying is wrong') puts the question to the case. ${ }^{5}$ The details of the case matter insofar as they bear on the answer to this question.

Particularists deny this. Particularists think that the rightness of a right act or judgment can be understood without reference to any such generalities. The morally significant details of the case owe their moral significance not to some abstract principle, but rather to each other. A morally important detail is morally important in virtue of its relation to the factual complex of which it is a part.

For example, consider the assassination of Julius Caesar. This was an illegal act, but everyone (generalists and particularists alike) recognises that one is sometimes morally obliged to break the law. So was it morally wrong? For a Kantian, the fact that this act was a murder makes it immoral. On this view, Kantian moral theory shows us that murder is wrong, and explains why it is wrong. With this general moral principle available, we know that Caesar's murder was wrong as soon as we know that it was a murder. For the particularist, however, general theories and principles do not decide the matter, because a single act cannot be understood in isolation. To treat a deed in this way is to abstract it from the complex of related events and circumstances that make it what it is, and thus to risk misjudging it. Caesar was murdered, but to judge this deed morally (as opposed to legally) we must know who murdered him, how, when, where and why. That is why particularism is sometimes described as a kind of holism. The moral rightness or wrongness of Caesar's assassination depends on its relations with all sorts of circumstances, in addition to those that identify it as a murder. Merely knowing that this deed was an instance of the general type murder is not, for the particularist, enough. 
To make sense of this, we should think of the act or judgment as a node in a vast and dense network of events and circumstances, none of which can be understood or correctly characterised in isolation. This recalls Butterfield's view that history is "the whole network produced by countless complications perpetually involving each other" (Butterfield 1931, 74-75). Earlier in the same work, Butterfield claims that the historian "tells us that a thing is good or harmful according to circumstances, according to the interactions that are produced" (Op. Cit. 58). For the moral particularist and for Butterfield's ideal historian alike, a human act gains its significance from its relations with surrounding circumstances and deeds. To bring a general principle or theory to bear on a human act, one must first abstract the act from its context, but this abstraction severs the very relations that give the act its moral meaning.

This holism has a consequence: the multi-valency of reasons. This means that (according to moral particularism) a feature can be right-making on one occasion, but wrong-making or ethically neutral on another. Suppose, for example, that a man driving his car at dusk sees a woman hitchhiking. In some circumstances, the fact that this hitchhiker is a woman would be a moral reason to give her a lift (if, say, there have been some attacks specifically against women in this area recently). In other circumstances, the same fact might be a morally compelling reason not to (suppose that this is a place where women face terrible consequences if they are seen talking to men other than their relatives). Finally, there are circumstances in which the sex of the hitchhiker is irrelevant. If the hitchhiker's sex always had the same ethical import, then we could hope to capture it in a principle. It might be a principle of Chivalry ('Always offer a lady a lift') or of Modesty ('Men should never speak to, let alone offer lifts to, women other than their immediate relatives'). The multi-valency of the 
hitchhiker's sex prevents this. Moreover, if we pretend otherwise and adopt a principled attitude to the sex of hitchhikers, we run the risk of making ethical errors: a male driver acting on a rigid principle of modesty might fail to stop for a woman who needs a lift for safety as well as transport; while a male driver acting on a principle of chivalry might cause a woman to be beaten up.

At this point, the dialectic as I present it favours particularism. Of course, the discussion does not end here. Generalists have counter-moves available to them. Generalists can re-describe these cases in generalist terms, and the debate then becomes a competition between re-descriptions. Particularists can always vary the case in view, in order to expose the rigidity of the generalists' principles. Generalists can respond in a variety of ways. They can add conditional clauses to their principles to deal with the difficult cases (e.g. a male driver should always offer a lift to a female hitchhiker except where local custom forbids it, unless there is an emergency or the hitchhiker is visibly indifferent to or independent from said local custom, etc.) — but such conditions quickly become $a d$ hoc and the original principles lose their original appeal as the emphasis gradually transfers from the original principles to the conditional clauses. Or, generalists can locate their principles at a higher level of abstraction (so the principle concerns, say, decency rather than chivalry or modesty) but this drains the principles of their content. ${ }^{6}$ Or, generalists may establish a system of principles with meta-principles to adjudicate cases in which first-order principles conflict—but this combines the drawbacks of the first two strategies. ${ }^{7}$ This dialectic can go on indefinitely. The particularist hopes to use a mass of case-studies to force the generalist into an unhappy choice between principles rendered empty by abstraction and principles rendered implausible by the addition of ad hoc clauses. 
Thus, particularism cannot defeat generalism in a single stroke but must instead aim to fell it with a thousand cuts. This could take some time.

Fortunately, this debate has happened before, in the philosophy of scientific methodology. It is to this earlier version that I now turn.

\section{Science}

Parallels between normative philosophy of science and ethical theory are not unprecedented. The most famous is probably Kuhn's claim that scientific standards function as values rather than as rules (Kuhn 1970, 184-6). What he meant is that it is easy to agree a list of desiderata for scientific theories: simplicity, generality, empirical adequacy, mathematical tractability, metaphysical plausibility, and so on. However, scientists do not recognise these desiderata in specific cases by applying criteria captured in a rule. Rather, scientists are able to recognise these valuable features in theories because they have been trained into an appropriate sensibility during their scientific apprenticeships. This emphasis on values and training makes Kuhn's philosophy of science sound rather like Aristotle's ethics. It would have been more accurate and more helpful if Kuhn had said 'virtues' rather than 'values'. Still, we can push this parallel a little further. Aristotle maintained that there can be no rule, however complex, that can codify the wisdom required for sound ethical judgment because (in Wiggins' paraphrase) “the subject matter of action (the province where it operates and field of things it is concerned with) is inexhaustibly indefinite" (Wiggins 2004, 480-1). Similarly, the endless variety of nature and of our efforts to understand it mean that sound scientific judgment cannot be codified. Duhem's insistence that scientists must employ uncodifiable scientific 'good sense' has a similarly Aristotelian ring, because his bon sens is not common sense. Rather, it is the 
product of years of training and practice. For Aristotle, Duhem and Kuhn, no abstract principles, however refined, can substitute for the trained eye and the practiced hand.

At this point, the parallel between Aristotle's ethics and Kuhn's philosophy of science breaks down. While Aristotle is usually confident that the wise will eventually agree on specific ethical cases, Kuhn insists that scientists who agree that generality (for example) is a virtue in theories can nevertheless have reasonable disagreements about what generality means in a given case (though he expects agreement among experts who have had the same training). Also, while Aristotle held that the human virtues form a unity, Kuhn held that the virtues of scientific theories are not even commensurable. That is to say, for Kuhn, given a trade-off between (for example) empirical adequacy and mathematical tractability, there is no exchange-rate with which we could calculate how much of one we should be prepared to give up for a given gain in the other. Moreover, Aristotle's ethics is ahistorical; he did not consider the central Kuhnian problem, that is, the transition from one normative sensibility to another. This is hardly surprising, as Kuhn had rather more human history to reflect on than did Aristotle, so the problem of rational transition between successive mentalities was more salient to him. These differences mark the limit of this parallel between Aristotle's ethics and Kuhn's philosophy of science, but what matters for the present purpose is their common view that sound judgment cannot be captured in a system of principles. They both insist that judgment depends on educated perception. They share this view with moral particularism, and some moral particularists cite Aristotle as a proto-particularist for this reason. ${ }^{8}$ However, neither Aristotle nor Kuhn are true particularists, because their virtues are not multi-valent. Magnanimity is always a good trait in people according to Aristotle, and generality is always a good feature of scientific theories according to Kuhn. 
If Kuhn's account of scientific judgment reminds us of Aristotle's ethics, then who is a particularist in the philosophy of science? The natural candidate is Feyerabend. ${ }^{9}$ He agreed with Kuhn and Duhem, among others, that scientific judgment is 'anarchic' in the sense that it cannot be summarised in a set of rules. Kuhn, though, expected scientists within a given paradigm to maintain a steady (Aristotelian) respect for the values of their scientific tradition and training, plus certain general methodological virtues. Feyerabend held that a steady respect for any abstraction, be it a rule, virtue or tradition, must eventually impair one's sensitivity to the situation at hand. For him, rules, principles and commitments to values are all potential obstacles to scientific progress. Thus, his view of scientific methodological principles probably comes closest to the pure particularist view of moral principles. This comes out in his debate with Lakatos, which followed from Popper's attempt to write down the logic of science, Kuhn's historicist challenge to Popper, and Lakatos' attempt to combine Popper's generalism with Kuhn's attention to historical detail. Lakatos hoped to find historically plausible ahistorical principles of scientific method with which to oppose what he saw as Kuhn's relativism. However, Lakatos was sensitive to Feyerabend's point that rigid methodological rules would inhibit the creativity of scientistssometimes it is important for a scientist to pursue an apparently unpromising hunch, or to stick with a theory in the face of apparently damning counter-evidence. So Lakatos developed his theory of 'research programmes'. Damning counter-evidence, on his view, does not matter so long as the programme is progressing (that is, making impressive and successful empirical predictions while elaborating its theoretical apparatus from its own conceptual resources). Degenerating programmes (that is, programmes making no progress and reduced to coping with adverse evidence by ad hoc means) should be starved of funds and institutional support. Finally, Lakatos 
recognised that a programme might degenerate for a time before reviving into a progressive phase. This last point gave Feyerabend his victory. Feyerabend pointed out that a programme might not revive if it is fatally starved of funds and support during its degenerative phase. Lakatos' methodology, for all its subtlety, falls to Feyerabend's point: any general principle can (and probably will) meet a situation in which it does more harm than good. Like the moral generalist, Lakatos (and before him, Popper) had to escape the charge of holding damagingly rigid principles, but the two available escape routes offer an unhappy choice between vacuous abstraction and ad hoc complexity. ${ }^{10}$ That is, a normative methodology of science must either become a formal abstraction (with only a tenuous connection to scientific practice), or it must be elaborated so that it gives the right advice on all occasions (but the circumstances of enquiry are inexhaustibly indefinite).

Studies by historians and philosophers less infamous than Feyerabend confirm that scientific reasoning is indeed particularist in structure. ${ }^{11}$ As in moral particularism, the chief part of the argument consists in pointing out the multi-valency of reasons. For example, naïve falsificationism held that if a theory is inconsistent with the results of an experiment, the theory must be abandoned. Man proposes; nature disposes. When theory and fact clash, surely the theory must give way. However, this view is excessively simple. Sometimes, an experimental or observational fact is a reason to give up a theory. On other occasions though, the contradiction of theory and fact may be a reason to give up the fact. That is, the apparent empirical fact may be an artefact of the experiment, and there may be good grounds to recognise this. Take the case of cold fusion: the theories that made cold fusion seem unlikely were much better confirmed than the measurements of excess heat that were supposed to show that cold fusion was taking place. Or, a contradiction between a theory and an experiment or 
observation may not be a reason for changing anything in the short term. If the theory is producing confirmed predictions and persuasive explanations in some other domain, and if the experiments seem sound, then it may be unwise to give up either, especially if there is at present no way to settle the matter without arbitrariness. The contradiction could be labelled 'an open problem' and left to one side until developments elsewhere yield new tools with which to work on it (the behaviour of comet tails and the anomalous perihelion of Mercury were open problems of this sort for Newtonian physics). Or scientists might decide to restructure the domain so that the awkward fact no longer falls within the scope of the theory (something like this happened in early modern studies of heat, which contracted to consider only combustion, leaving the heat generated by animals' bodies aside). Or it may be possible to redescribe the data in a way that resolves the contradiction. And so on. There is no general recipe to tell a scientist what to do when faced with a contradiction between theory and data. Nor is there any hope of specifying in advance a finite list of possible options. ${ }^{12}$ None of this entails that scientific practice is dangerously irrational or unreliably subjective. It merely shows that empirical scientific reasoning is particularist in structure.

In the next section, I wish to carry this argument into mathematical practice. First, however, I wish to set aside a possible confusion. One might think that the highly general scope of physical laws entails that they must be arrived at by generalist means. This does not follow. Truths in fundamental physics are true at all times and places, but they are arrived at and justified by context-specific arguments with a particularist structure. A result is established, or doubted, or refuted, or set aside as an open problem for reasons that depend on what else the scientists believe at the time about the structure of the universe and also about the reliability of specific 
experiments (to mention just one of the many circumstances that might bear on such judgments). The highly general scope of fundamental physics in no way requires that reasoning about fundamental physics should be generalist. To see this, consider time. Scientific reasoning is temporal in the sense that it depends on its own history. We hold the scientific theories that we do in part because they superseded our previous theories; they are our least lousy theories so far. ${ }^{13}$ On the other hand, the results of fundamental physical science are tenseless. Whenever the conditions of the theory hold, the laws hold. As with time so with space; the reasoning is local even though the resulting laws hold everywhere in the universe.

The point is that particularism is a view about reasons; it is not about causes. Nature, as described by the natural sciences, does conform to general laws, while human reasoning and reasoned action do not, except for laws of logic so abstract that they leave almost all the work of judgment undone. Natural events may be understood in isolation without fear of distortion. For example, we can understand the physics of a collision between two objects if we know what they are composed of, how fast they are travelling, and in what directions. We do not need to know how the objects came to be on those trajectories, or whether this was the first collision between them. In contrast, suppose two people meet. It may make a difference to the significance of the meeting if they were looking out for each other, or if they met regularly, or just happened to bump into each other. Without knowing this, we do not know what sort of event it is: a fortuitous encounter or a rendezvous. This may make all the difference in, for example, divorce proceedings. ${ }^{14}$ Without setting the encounter in context, we cannot describe it, let alone explain how it turned out. We can understand physical collisions by citing laws, precisely because physical collisions do not depend essentially on their contexts. ${ }^{15}$ 
Truths in pure mathematics are yet more general than those in fundamental physics, but reasoning about them is nevertheless particularist in structure. In the next section, I suggest that mathematical reasoning has the multi-valent structure identified by Dancy: that the same feature can be a reason for different beliefs and actions on different occasions.

\section{Mathematics}

One might suppose that the rationality that guides and secures mathematical progress is pretty well exhausted by the formal theory of deduction. Where empirical scientists have their experimental reasoning, mathematicians have their proofs, and these, one might think, always conform to the same rules. Thus, mathematics seems to provide the paradigmatic case of generalist reasoning. For surely (runs the thought) the argument for particularism in the case of scientific reasoning cannot be reproduced here. There are no unreliable experiments or misinterpreted observations in pure mathematics. If a hypothesis entails a contradiction, mathematicians must surely abandon it. On the other hand, if particularism (holism about reasons) is true of all reasoning, then a fortiori it must be true of mathematical reasoning. As I said at the outset, defenders of an unrestricted particularism about reasons must make the case for particularism with respect to every kind of reason, including mathematical reasons. ${ }^{16}$

Ideally, one would illustrate this argument with the latest and best mathematics. There are philosophical studies of contemporary advanced mathematics that one

might turn to that end, just as there are for empirical science. ${ }^{17}$ However, the point of this paper is to connect hitherto isolated philosophical discussions. I would not serve this purpose by presenting ethicists with examples drawn from the frontiers of 
contemporary mathematics. Instead, I shall appeal to one of the founding texts in this sort of approach to mathematics: Lakatos' Proofs and Refutations.

Proofs and Refutations tells the story of a mathematical conjecture, from its origin as a geometrical hypothesis to the point at which it ceases to depend on our spatial intuitions and becomes a piece of abstract mathematics. This story is the vehicle for a
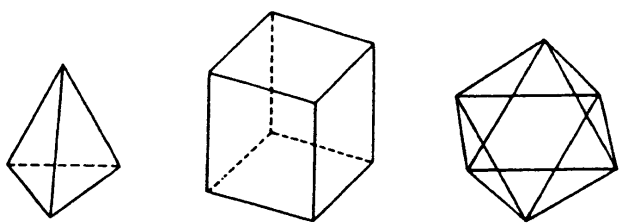
mathematics. This story is the vehicle for a
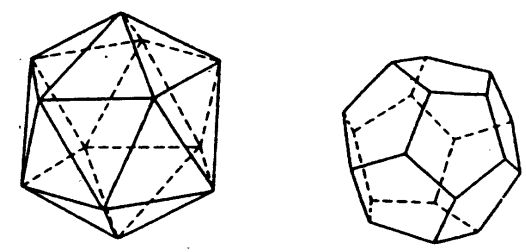
discussion of mathematical practice and the philosophy of mathematical research. It takes place in a fictional classroom dialogue while Lakatos discusses the real history in his footnotes. From these footnotes, we learn that the various methodological moves made and philosophical stances taken by the characters in the dialogue were borrowed from real historical mathematicians. Lakatos was not making it up. ${ }^{18}$

The conjecture is in solid geometry. It is that for any polyhedron, the number of faces minus the number of edges plus the number of vertices equals two. For example, a cube has six faces, twelve edges and eight vertices. So in this case, the sum is $6-12+8=2$. A tetrahedron has four faces, six edges and four vertices: $4-6+4=2$. This formula holds for all the familiar regular polyhedra (exercise: check the remaining three platonic solids). But does it hold generally? The short answer is 'no'. There are solids for which the formula does not hold, such as some solids with tunnels through them, or step-pyramids. Consider the solid cube with a cubic space in the middle (illustrated). For this object, the alternating sum of faces, edges and vertices comes to four. We now have at least four options: we could abandon the conjecture because it has a counterexample; we could refuse to accept the hollow cube as a counterexample because it is not a 'proper' polyhedron; we could redescribe 
it so that the contradiction dissolves; or we could keep both the conjecture and the counterexample while we try to advance the field as a whole to the point where we could make a satisfactory judgment. If we have an attempted proof of the conjecture, we can engage in proof-analysis with the hollow cube in mind. Lakatos' dialogue explores all of these options. It turns out that, as in empirical science, each of these reactions to a counterexample is appropriate on some occasions. What we ought not to do is react in the same way every time. Sometimes, a deep idea finds expression in a neat theorem. If we reject every conjecture that suffers a counterexample, we may lose such theorems, and gain little in return. Instead, we have the option of adjusting definitions so that the 'counterexamples' cease to threaten the theorem (in this case, we might decide that 'proper' polyhedral solids do not have cavities). On the other hand, if we always defend conjectures against counterexamples by insisting that the apparent counterexample does not really fall under the conjecture (as we might insist that a step-pyramid is not really a polyhedron) our conceptual innovations will always be conservative and often ad hoc. Sometimes the presentation of a weird object (such as, say, a space-filling curve, or a function that is everywhere continuous but nowhere differentiable) will force mathematicians to rethink more profoundly a body of knowledge that had seemed familiar and settled (and there is no finite list of procedures that add up to 'rethinking more profoundly'). Finally, we cannot always defer judgment, or there would be nothing but open problems. Here, in mathematics, we have the holism of reasons. The same reason (the presence of a counterexample to an accepted conjecture) can point in opposing directions or in none, depending on the details of the situation. There is no rulebook or set of methodological principles for deciding how to respond in any given case. Mathematicians want theorems and proofs that are deep, fruitful and elegant, and there is no recipe for these. ${ }^{19}$ 
Lakatos' discussion immediately introduces an attempt to prove the conjecture, and this allows him to explore the justificatory practices of pure mathematics. Proofs are not merely means for recognising truths. On the contrary, proof-ideas can be some of the deepest and most interesting ideas in mathematics. The mathematician Yehuda Rav claims that "Theorems are only the headlines; proofs are the real story" (Rav 1999, 22). The important point here is that the justification of a theorem requires more than a valid proof. We need to show that the concepts and definitions employed in the theorem are well-chosen and that the original question is worth pursing. In this sense, a proof that a chess-problem has a solution in a given number of moves may be valid, but the whole enterprise may be unjustified because there is no mathematical insight to be had (G.H. Hardy called chess-problems "the hymn tunes of

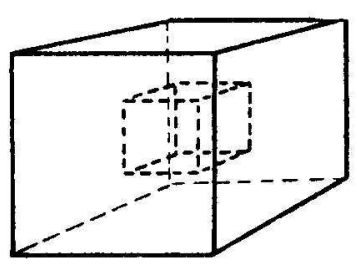
mathematics" 199287 ). A proof can contribute to the justification of concepts and definitions in this larger sense; insofar as a proof is insightful as well as valid, the concepts and definitions it employs are thus far

vindicated.

In the case at hand, the first proof that Lakatos considers suggests criteria for identifying 'real' polyhedra (it is a sort of topological thought-experiment that cannot be performed on objects with cavities, so if we adopt this proof then we have to refuse these objects the status of polyhedron and consequently they are no longer counterexamples to the theorem). In the end, in this case, the preferred option is to keep both the counterexample and the conjecture in mind while the discussion goes in search of a deeper understanding of polyhedral surfaces. To get a sense of what this means, look again at the diagram of the cube with a cubic space inside. The Eulernumber (faces minus edges plus vertices) for this solid is four. But consider it now 
not as a solid, but as a pair of surfaces, one inside the other. For each of these surfaces, the Euler-number is two. That is, our conjecture is true of each of these surfaces considered separately. So instead of just abandoning the conjecture in the face of the counterexample, we can rethink it so that it survives in a deeper form. It has become a conjecture about surfaces rather than solids. Now we can ask: of which surfaces is it true?

At this point, the question is passing from geometry to topology. To see this, consider that you could make the surface out of different coloured canvas panels and it would not matter whether it were stretched taut or not, so long as we could identify faces, edges and vertices. For example, the conjecture may be true of a tent with a sewn-in groundsheet (depending on the design). It does not matter whether the tent is erected or not. (Exercise: is the Euler conjecture true of a duvet-cover?) ${ }^{20}$ In fact, we can push a bit further. Does the conjecture hold for a surface whose panels pass through each other? This is rather hard to imagine so long as we think of the faces as made of some material like canvas. But go back to the cube with a cubic space inside. Think of the two cube-shaped surfaces not as two surfaces but as two wire frames. Or to return to tents: we can see whether the conjecture holds of a given tent just by looking at the frame, provided the seams of the canvas correspond to the poles of the tent. ${ }^{21}$ When we think of the hollow cube as a pair of cube-shaped frames, we can see that their spatial relationship does not matter. The conjecture is true of each of them separately, and would remain so even if they were tangled together rather than neatly nested. So now the question is: of which wire frames is the conjecture true? This question takes the problem into algebraic topology, where we shall not follow it. It is enough to see that this question — about wire frames-allows us to answer questions about polyhedral surfaces and solids that we could not answer so long as we were 
thinking directly about surfaces and solids. The point is that following a general methodological principle — any general methodological principle, or even a finite set of conjoined general methodological principles - in the face of a range of counterexamples would not have brought us to this deeper understanding of the phenomenon.

\section{Conclusion}

If particularism is true, then holism about reasons must be true, not only in the case of moral reasoning but of every sort of reason. In that case, holism about reasons must be true of scientific and mathematical reasoning. This leads to a familiar debate about the extent to which sound scientific practice can be captured in a system of general principles. The heroic phase of this debate (Popper-Kuhn-Lakatos-Feyerabend) is now a standard part of the undergraduate curriculum. Since then, philosophers of science have either abandoned the notion of a universal scientific method, replaced it with something much looser (like Kuhn's list of desiderata), ${ }^{22}$ or retreated to the safety of abstract logical theory. ${ }^{23}$ In the case of mathematics, the corresponding debate is rather less well developed, though the materials for it are increasingly available. ${ }^{24}$ As with empirical science, attention to practice encourages the claim that a reason (in this case the combination of conjecture and counterexample) might point in any one of three ways depending on the overall state of the argument at the time. Holism is not, as Dancy supposes, uncontroversially true of theoretical reasons. But if the argument presented here is sound then it is true, even in those theoretical domains that seem, at first glance, least hospitable to it. At the very least, I have shown that particularism stands or falls on the same ground in the ethical, scientific and mathematical cases. This is what one would expect, given that it is a view about 
reasons that just happens, contingently, to have been chiefly explored in the moral case.

School of Humanities

University of Hertfordshire

Hatfield

Hertfordshire

AL10 9AB

UK

b.p.larvor@herts.ac.uk 


\section{References}

Butterfield, Herbert. 1931. The Whig Interpretation of History. London: Bell (reprinted by Penguin, 1973).

Collingwood, Robin. 1994. The Idea of History (revised edition). Oxford: Oxford University Press.

Corfield, David. 2003. Towards a Philosophy of Real Mathematics. Cambridge: Cambridge University Press.

Cullity, Garrett. 2002. "Particularism and Moral Theory: Particularism and Presumptive Reasons.” Proceedings of the Aristotelian Society Supplementary Volume 76: 169-90.

Dancy, Jonathan. 1983. "Ethical Particularism and Morally Relevant Properties." Mind 92: 530-47.

Dancy, Jonathan. 1993. Moral Reasons. Oxford: Blackwell.

Dancy, Jonathan. 2000. “The Particularist's Progress" in Moral Particularism edited by Brad Hooker and Margaret Little, 130-156. Oxford: Oxford University Press.

Dancy, Jonathan. 2004. Ethics Without Principles. Oxford: Clarendon Press.

Davis, Philip \& Hersh, Reuben. 1990. The Mathematical Experience. Penguin Books Ltd.

Duhem, Pierre. 1954. The Aim and Structure of Physical Theory. Princeton University Press. Tr. Philip Wiener. Originally published in French, 1906. 
Dworkin, Gerald. 1995. "Unprincipled Ethics." Midwest Studies in Philosophy 20: Moral Concepts: 224-39

Feyerabend, Paul. 1993. Against Method ( $3^{\text {rd }}$ edition). London: Verso. First edition 1975.

Friend, Michèle; Goethe, Norma B.; Harizanov, Valentina S. (Eds.) 2007. Induction, Algorithmic Learning Theory, and Philosophy. Springer.

Galison, Peter. 1987. How Experiments End. University Of Chicago Press

Grosholz and Breger (eds). 2000. The Growth of Mathematical Knowledge. Dordrecht: Kluwer.

Hardy, G.H. 1992. A Mathematician's Apology. Cambridge: Canto (first edition 1940).

Hegel, G. 1967. Hegel's Philosophy of Right. Tr. T.M. Knox. Oxford: Oxford University Press.

Hooker, B. W. and Little, M., (eds). 2000. Moral Particularism. Oxford: Oxford University Press.

Jonsen, A. R. and Toulmin, Stephen. 1988. The Abuse of Casuistry: A History of Moral Reasoning. Berkeley: University of California Press.

Kant, Immanuel. 1987. Critique of Judgement. (trans. W. S. Pluhar). Indianapolis: Hackett, (first published 1790).

Kant, Immanuel. 1999. Immanuel Kant: Practical Philosophy. (trans. M. J. Gregor) Cambridge: Cambridge University Press. 
Kelly, Kevin. 1996. The Logic of Reliable Inquiry. Oxford: Oxford University Press.

Kihlbom, Ulrik. 2002. Ethical Particularism: An Essay on Moral Reasons. Stockholm: Springer.

Kitcher, Philip. 1993. The Advancement of Science: Science Without Legend, Objectivity Without Illusions. Oxford: Oxford University Press.

Kuhn, Thomas. 1970. The Structure of Scientific Revolutions. Chicago: University of Chicago Press ( $2^{\text {nd }}$ edition).

Kuhn, Thomas. 1977. The Essential Tension: Selected Studies in Scientific Tradition and Change. Chicago: University of Chicago Press.

Lakatos, Imre. 1976. Proofs and Refutations: the logic of mathematical discovery. Cambridge: Cambridge University Press.

Lakatos, Imre. 1978. The Methodology of Scientific Research Programmes. Edited by John Worrall and Gregory Currie. Cambridge: Cambridge University Press.

Larvor, Brendan. 1998. Lakatos: an introduction. London: Routledge.

Larvor, Brendan. 2001. "What is dialectical philosophy of mathematics?" Philosophia Mathematica 9/2: 212-29.

Leng, Mary. 2002. "Phenomenology and Mathematical Practice.” Philosophia Mathematica 10/1: 3-25.

MacIntyre, Alasdair. 1977. "Epistemological Crises, Dramatic Narrative and the Philosophy of Science." The Monist, 60: 453-72. 
Motterlini, Matteo. 1999. For and Against Method. Chicago: University of Chicago Press.

Rav, Yehuda. 1999. "Why do we prove theorems?" Philosophia Mathematica 7/1: 5-41.

Rota, Gian-Carlo. 1997. "The Phenomenology of Mathematical Proof." Synthese 111/2: 183-196.

Singleton, Jane. 2004. "Neither Generalism nor Particularism: Ethical Correctness is Located in General Ethical Theories.” Journal of Moral Philosophy 1, no. 2: $155-175$

Sinnott-Armstrong, Walter. 1999. "Some Varieties of Particularism." Metaphilosophy 30: 1-12.

Waller, John. 2004. Leaps in the Dark: the making of scientific reputations. Oxford: Oxford University Press.

Wiggins, David. 2004. “Neo-Aristotelian Reflections on Justice.” Mind 113/451: 477-512. 
${ }^{1}$ For example: Cullity 2002; Dancy 2004; Dworkin 1995; Hooker and Little 2000; Jonsen and Toulmin 1988; Sinnott-Armstrong 1999.

2 "The debate between [generalists and particularists] tends to turn on the rights and wrongs of two other views, which have nothing especially to do with morality at all." (Dancy 2004, 7). The two views are holism and atomism about reasons. See Dancy $2000,132 \mathrm{ff}$ for his claim that particularism is uncontroversially true in epistemology and practical reasoning; regarding the philosophy of science, see Dancy 2004, 74 "generalism is uncontentiously false of theoretical reasons".

${ }^{3}$ That is, particularism about all reasons, in contrast particularism restricted to a specific domain such as morality.

${ }^{4}$ It is a subtle question how many generalists there are among specialist philosophers of science. Relatively few nowadays think that there is a set of methodological principles that jointly constitute the scientific method. See next section.

${ }^{5}$ In the manner of a magistrate, to take up Kant's simile (Critique of Pure Reason Bxiii).

${ }^{6}$ Thus for Hegel, Kant's moral philosophy was an empty formalism that Kant filled with the ethical life of Eighteenth Century Königsberg. See Hegel's Philosophy of Right $\$ 135$.

${ }^{7}$ There is an option similar to this last which appeals to practical judgment to adjudicate conflicts between first-order principles. This 'pluralist' option shares with particularism the burden of explaining without mystification how practical judgment works in the absence of principles (since at the meta-level, the pluralist sees no metaprinciple governing the first-order principles), but cannot claim, as particularism can, to respect the indefinite variety of moral experience (since pluralism insists that there 
is a finite set of first-order principles). Moreover, while particularist practical judgment occurs at the ground level, and is thus rooted in practical life, pluralist 'practical' judgment occurs at the meta-level and is thus deprived of the nourishment of the life-world.

${ }^{8}$ I am grateful to an anonymous referee for this point. See Irwin in Hooker \& Little 2000.

${ }^{9}$ Specifically, the Feyerabend of Against Method.

${ }^{10}$ See Lakatos 1978 chapters 2 and 3 for Lakatos' theory of science; Feyerabend 1993 for Feyerabend's critique (this was intended to be a joint work, but neither would cede the other the last word before Lakatos died). See also Motterlini 1999 for the surviving Lakatos-Feyerabend correspondence on this and other topics. See Larvor 1998, 80-85 for more on the Lakatos-Feyerabend dialectic.

${ }^{11}$ For example, Peter Galison 1987; John Waller 2004.

12 That is why pluralism does not offer a safe last ditch to the retreating generalist. See footnote 7 above.

${ }^{13}$ This we owe largely to Popper. See also MacIntyre 1977.

${ }^{14}$ The agent of a famous footballer was seen in a restaurant talking to the assistant manager of a rival club. It was, they insisted, an accidental meeting. A rendezvous would have been illegal.

${ }^{15}$ Here is another historian insisting that history has a different mode of explanation to natural science: "If history is explanatory, that is not because its narratives are covered by general laws. Rather it is because the reader who says 'Now I know what happened,' is simultaneously saying, 'Now it makes sense; now I understand; what was for me previously a mere list of facts has fallen into a recognizable pattern."” (Kuhn 1977, 17-18). 
${ }^{16}$ Obviously, if the multi-valency of reasons is true all reasons, it is true of philosophical reasons. A philosophical consideration that favoured particularism in ethics might (for all we know, before we consider cases in detail) favour generalism in some other domain. That is why there cannot be a general argument for unrestricted particularism.

${ }^{17}$ See works in references by Corfield, Davis \& Hersh, Leng, Rav, Rota and Grosholz and Breger. None of these has adopted, or rejected, the epithet 'particularist'.

${ }^{18}$ Which is not to say that his history is beyond criticism. Corfield $(2003,157)$ notes that Lakatos recounts the story up to the 1860s, and then introduces Poincaré's proof of 1899 without any mention of the intervening events. This is only the most grotesque of many distortions of the history of algebraic topology forced on Lakatos by his focus on a single conjecture. Nevertheless, the footnotes do establish that the methodological and philosophical stances appearing in the dialogue are those of real mathematicians rather than straw men.

${ }^{19}$ So here again, the pluralist compromise is impossible. See footnotes 7 and 12 above.

${ }^{20}$ It depends what you mean by 'vertex'. If we count the corners as vertices, a duvetcover made of two panels has four vertices, four edges and two faces, the alternating sum of which adds up to two (so the conjecture is true of it). The point is that this calculation does not change however the duvet-cover is folded, which is why the conjecture belongs to topology rather than geometry.

${ }^{21}$ We also need to know a bit about the design of the door-flap, but this consideration is hardly helpful here. 
${ }^{22}$ E.g. Kitcher 1993.

${ }^{23}$ E.g. Kelly 1996. See Friend, Goethe \& Harizanov 2007 for essays on this approach. Bayesianism is another popular variety of abstract normative theory.

${ }^{24}$ See Corfield 2003 and Larvor 2001 for the claim that Lakatos' argument can, after some modification, be extended to more recent mathematics that does not depend on spatial intuition. 